Challenges Surrounding the Injection and Arrival of Targets at LIFE Fusion Chamber Center

R. Miles, M. Spaeth, K. Manes, P. Amendt, M. Tabak, T. Bond, S. Kucheyev, J. Latkowski, G. Loosmore, E. Bliss, K. Baker, S. Bhandarkar, R. Petzoldt, N. Alexander, M. Tillack, D. Holdener

January 5, 2011

Fusion Science and Technology as part of the Proceedings of the Nineteenth Topical Meeting on the Technology of Fusion Energy (TOFE) 
This document was prepared as an account of work sponsored by an agency of the United States government. Neither the United States government nor Lawrence Livermore National Security, LLC, nor any of their employees makes any warranty, expressed or implied, or assumes any legal liability or responsibility for the accuracy, completeness, or usefulness of any information, apparatus, product, or process disclosed, or represents that its use would not infringe privately owned rights. Reference herein to any specific commercial product, process, or service by trade name, trademark, manufacturer, or otherwise does not necessarily constitute or imply its endorsement, recommendation, or favoring by the United States government or Lawrence Livermore National Security, LLC. The views and opinions of authors expressed herein do not necessarily state or reflect those of the United States government or Lawrence Livermore National Security, LLC, and shall not be used for advertising or product endorsement purposes. 


\title{
CHALLENGES SURROUNDING THE INJECTION AND ARRIVAL OF TARGETS AT LIFE FUSION CHAMBER CENTER
}

\author{
Robin Miles ${ }^{1}$, Mary Spaeth ${ }^{1}$, Ken Manes $^{1}$, Peter Amendt ${ }^{1}$, Max Tabak ${ }^{1}$, Tiziana Bond ${ }^{1}$, Sergei Kucheyev ${ }^{1}$, Jeff Latkowski ${ }^{1}$, \\ Gwen Loosmore ${ }^{1}$, Erlan Bliss ${ }^{1}$, Kevin Baker ${ }^{1}$, Suhas Bhandarkar ${ }^{1}$, Mark Havstad ${ }^{1}$, Ron Petzoldt ${ }^{2}$, Neil Alexander ${ }^{2}$, Mark \\ Tillack $^{3}$, Dain Holdener ${ }^{3}$ \\ ${ }^{1}$ Lawrence Livermore National Laboratory: P. O. Box 808/L-223, Livermore CA, 94551, miles7@llnl.gov \\ ${ }^{2}$ General Atomics, San Diego, CA, ronald.petzoldt@gat.com \\ ${ }^{3}$ University of California - San Diego, La Jolla, CA
}

IFE target designers must consider several engineering requirements in addition to the physics requirements for successful target implosion. These considerations include low target cost, high manufacturing throughput, the ability of the target to survive the injection into the fusion chamber and arrive in a condition and physical position consistent with proper laser-target interaction and ease of post-implosion debris removal. This article briefly describes these considerations for the Laser Inertial Fusion-based Energy (LIFE) targets currently being designed.

\section{INTRODUCTION}

Fuel targets for commercial fusion reactors must satisfy multiple requirements to achieve successful implosion beyond the target physics specifications. These requirements include cost-effective, high throughput manufacture, the ability to handle the acceleration forces of injection into the fusion chamber, the ability to maintain a cold DT temperature during flight through the hot fusion chamber, the ability to evacuate and reprocess the post-implosion debris from the chamber and the ability of the driver beams to penetrate remaining debris suspended in the chamber atmosphere. A preliminary point-design target is currently being designed to satisfy these demands for the proposed Laser Inertial Fusionbased Energy (LIFE) plant concept, currently under development, which uses multiple laser-beam drivers for ignition. Parameters of the system relevant to the LIFE target design are listed in Table 1.

The current target concept is shown in Fig. 1. The physics design features a $\sim 4 \mathrm{~mm}$ diameter hollow spherical capsule inside $\mathrm{a} \sim 1 \mathrm{~cm}$ inner diameter by $\sim 2 \mathrm{~cm}$ long hohlraum. The CVD diamond capsule ablator wall thickness is slightly less than $100 \mu \mathrm{m}$ and the inner deuterium-tritium (DT) layer is about $150 \mu \mathrm{m}$ thick. The hohlraum has a rugby shaped interior for better coupling of the $\sim 2.4$ MJ laser energy to the capsule and P2 shield for even greater efficiency. The hohlraum currently consists of a thin layer of plated lead ( $20-50 \mu \mathrm{m}$ thick) on the inside of the hohlraum for the conversion of the laser light to x-ray radiation, supported by an insulating injection-molded plastic hohlraum structural substrate. The physics design of the target is discussed in greater detail in Ref. 1.

TABLE I. LIFE Target-Relevant Requirements

\begin{tabular}{|l|c|}
\hline \multicolumn{1}{|c|}{ Parameter } & Value \\
\hline Per-target cost & $<30$ cents \\
\hline Repetition rate & $\mathbf{1 0 - 2 0 ~} \mathbf{~ H z}$. \\
\hline Injection acceleration rate & $\sim 6000 \mathrm{~m} / \mathbf{s}^{\mathbf{2}}$ \\
\hline Injection exit velocity & $\sim 250 \mathrm{~m} / \mathbf{s}$ \\
\hline Chamber gas temperature & $\mathbf{6 0 0 0}-\mathbf{8 0 0 0 K}$ \\
\hline Chamber gas pressure & $\sim 23 \mathrm{Torr}$ \\
\hline Chamber wall temperature & $\sim 900 \mathrm{~K}$ \\
\hline Chamber radius & $\sim 6 \mathbf{m}$ \\
\hline $\begin{array}{l}\text { Maximum allowable DT } \\
\text { temperature change }\end{array}$ & $\sim 100 \mathrm{mK}$ \\
\hline
\end{tabular}

\section{THERMAL CONSIDERATIONS}

A decision was made early in the LIFE plant concept to protect the first wall from the assault of ions and much of the prompt $\mathrm{x}$-ray radiation produced during implosion by introducing a low pressure ( $\sim 23$ torr) Xe atmosphere into the $\sim 12 \mathrm{~m}$ diameter chamber. ${ }^{2}$ While this permits the use of more conventional materials for the first wall, ${ }^{2}$ this increases the difficulty in maintaining the DT layer temperature at $\sim 19 \mathrm{~K}$ during flight though this atmosphere which remains at temperatures at up to $\sim 8000 \mathrm{~K}$. Ideally, the hohlraum substrate will insulate the capsule from the hot Xe gas during the $\sim 24 \mathrm{~ms}$ flight time through the chamber. 


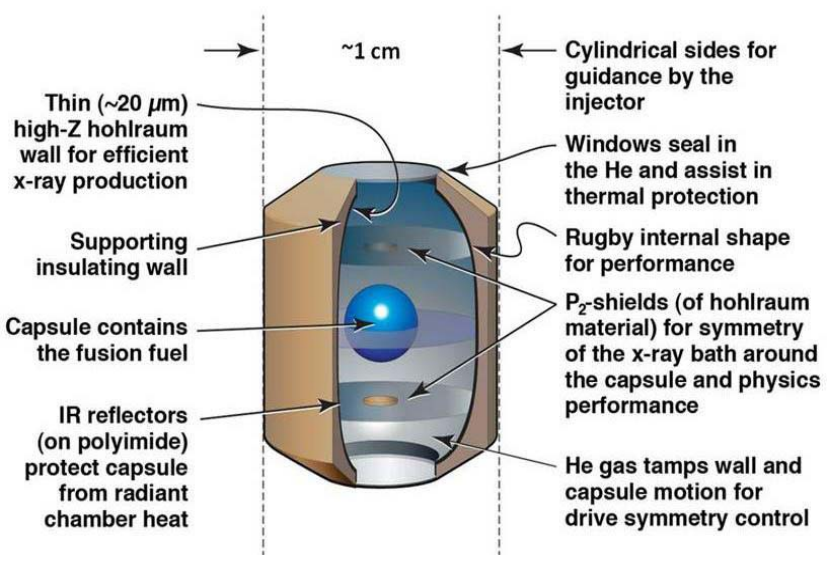

Fig. 1. LIFE point-design target.

The thin ( $\sim 500 \mathrm{~nm}$ thick graphene) laser entrance hole (LEH) window heats up rapidly in the $\sim 8000 \mathrm{~K} \mathrm{Xe}$ atmosphere to $\sim 2200 \mathrm{~K}$ but stays below the temperature limit of graphene $(\sim 3000 \mathrm{~K})$. The $\sim 1 \mathrm{gm} / \mathrm{cc}$ helium atmosphere in the hohlraum transports heats to the hohlraum which acts as the thermal heat sink as shown in Fig 2. The infra-red (IR) radiation from the $900 \mathrm{~K}$ chamber walls reflects off the IR shields inside the hohlraum which are comprised of a thin polyimide membrane $\sim 400 \mathrm{~nm}$ in thickness coated with $\sim 30 \mathrm{~nm}$ of metalized aluminum. The IR shield heats the helium near the capsule. The DT temperature raises about $80 \mathrm{mK}$ which is below the $100 \mathrm{mK}$ specification for it change in temperature. To keep the target cooler, the target could be injected coincident with a cooler Xe gas jet in future designs.

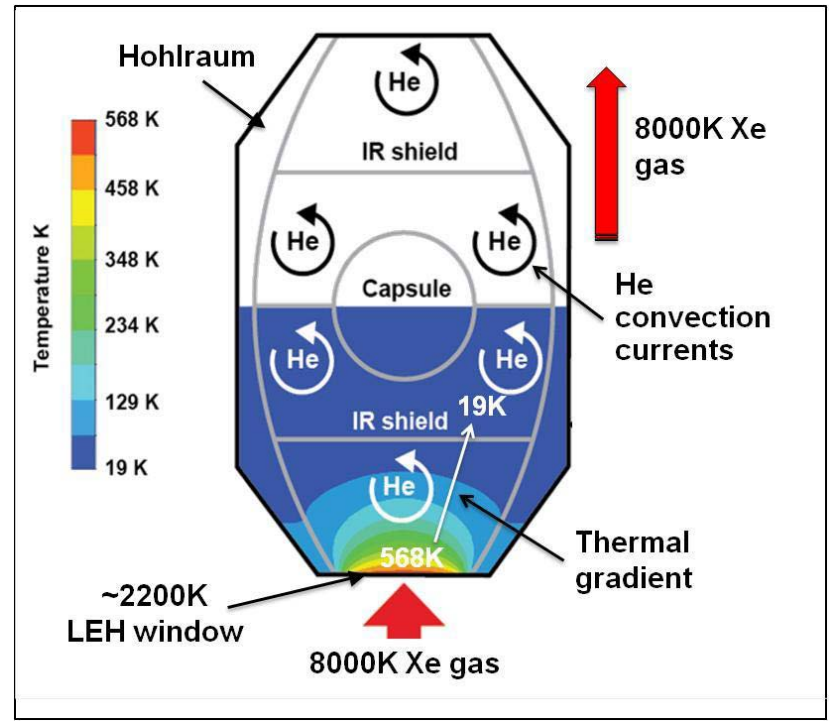

Fig. 2. Thermal analysis shows heating of the LEH window and $\mathrm{He}$ gas by the Xe chamber gas.

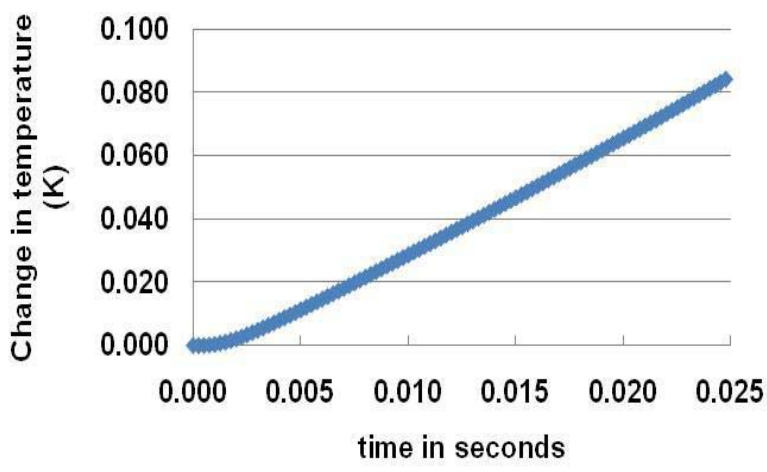

Fig. 3. Temperature rise of the DT in the capsule is less than the $0.100 \mathrm{~K}$ specification.

\section{STRUCTURAL CONSIDERATIONS}

The hohlraum can be made robust to the $\sim 600 \mathrm{~g}$ acceleration forces through choice of materials and wall thickness. The more fragile components of the target are the DT layer and the $\sim 110 \mathrm{~nm}$ thick polyimide capsule support membrane. Little data is available describing the structural strength of DT ice although some data of hydrogen and deuterium exists. ${ }^{3}$ Hydrogen isotopes have high affinity to other materials. ${ }^{3}$ If the DT layer adheres to the ablator then the ablator can act as a structural support for the DT layer. A preliminary 2D analysis indicates that a stiff CVD diamond ablator coupled with a layer of deuterium indicates a deformation of the capsule of $<1$ um out-of-round which is within the current allowable LIFE deformation limit.

Preliminary models of the capsule support membrane using membrane data taken for National Ignition Facility (NIF) targets shown in Fig. 4 and applied to Timoshenko's membrane deflection equations ${ }^{4}$ suggest that the membrane will remain intact up to acceleration rates of $600 \mathrm{~g}$ provided that the membrane is molded to conform to the shape of the capsule and annealed to remove any stress induced during the loading of the capsules into the membrane. In this case, the acceleration forces are the only forces affecting membrane deflection. Another technique to reduce membrane forces and deflections is to orient the capsule support membranes in the direction of the acceleration forces as shown in Fig. 5 for a cylindrical hohlraum. The membrane is anchored to the hohlraum structure partition line which is also oriented axially. In this case it is expected that the tolerable acceleration rate will exceed $1000 \mathrm{~g}$. Future work will entail measurement of the material properties for candidate materials at cryogenic conditions and finite element analyses of the thin membranes to confirm that the support membrane will survive both the static and dynamic forces of injection acceleration. 


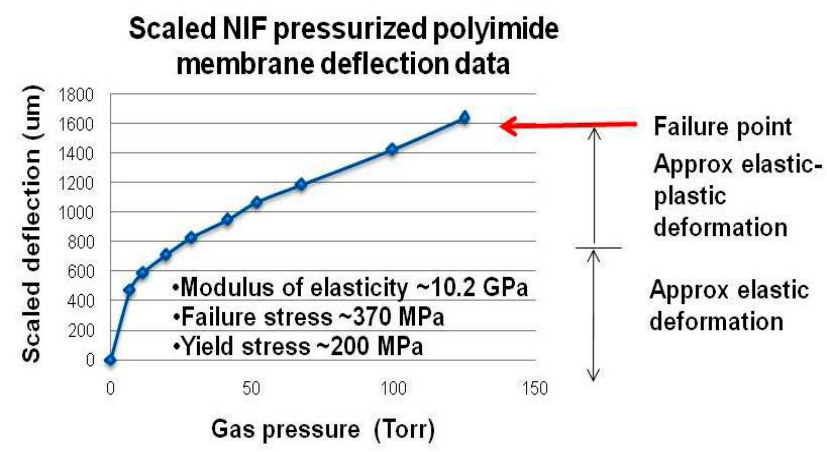

Fig. 4. Deflection versus pressure data taken on NIF polyimide membranes at cryogenic temperatures $(15 \mathrm{~K})$.

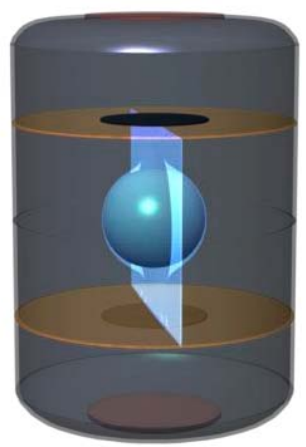

Fig. 5. Axially oriented capsule support membrane to reduce stresses and deflections of the membrane

\section{MATERIAL CONSIDERATIONS}

Removal of the debris from the chamber following the implosion and subsequent recycling and/or disposal impose design constraints for target material selection particularly for the hohlraum material which constitutes the majority of the mass of the target. The hohlraum consists of an inner high- $\mathrm{Z}$ layer for $\mathrm{X}$-ray production, a thermally insulating-structural support material and possibly an additional conductive outer layer if an induction injector or an electro-magnetic trajectory steering section are used for injection. The ideal materials will have a melting temperature lower that the wall temperature of $900 \mathrm{~K}$ so that solid deposits will not accumulate on the chamber wall and either alter the thermal or neutronic characteristics of the wall or flake off creating a cloud of solid debris near the wall which could reduce the laser propagation or damage the targets entering the chamber. Materials with a high vapor pressure can be continuously pumped out of the chamber for easy removal. Further discussion of chamber clearing can be seen in ref. 2 .
The laser propagation through the residual vapor must be considered. Absorption lines near the laser frequency which result in Stokes shifted Raman scattering must be carefully analyzed to determine if this effect will significantly affect the amount of laser light reaching subsequent targets. Lead is an attractive high- $Z$ hohlraum material because it is inexpensive, has low-level activation products and is easily manufactured through swaging or plating. However, lead vapor is a known Raman scattering media whereas, an alternative high- $Z$ material, mercury, is not. Pure mercury, however, with a melting point of $\sim 234 \mathrm{~K}$ requires additional expense to maintain a cold manufacturing environment. Lead remains under consideration for the high- $\mathrm{Z}$ as ionized lead which will probably be generated soon after the start of the laser pulse may be acceptable for laser propagation.

Less expensive materials with low-radiation activation levels such as lead could be discarded as lowlevel waste or recycled if these recycling costs are low. Materials which may present a waste-disposal problem should be avoided. Cost, vapor-pressure based debris removal and waste disposal selection criteria for the high$\mathrm{Z}$ layer of the hohlraum are summarized in Fig. 6 .

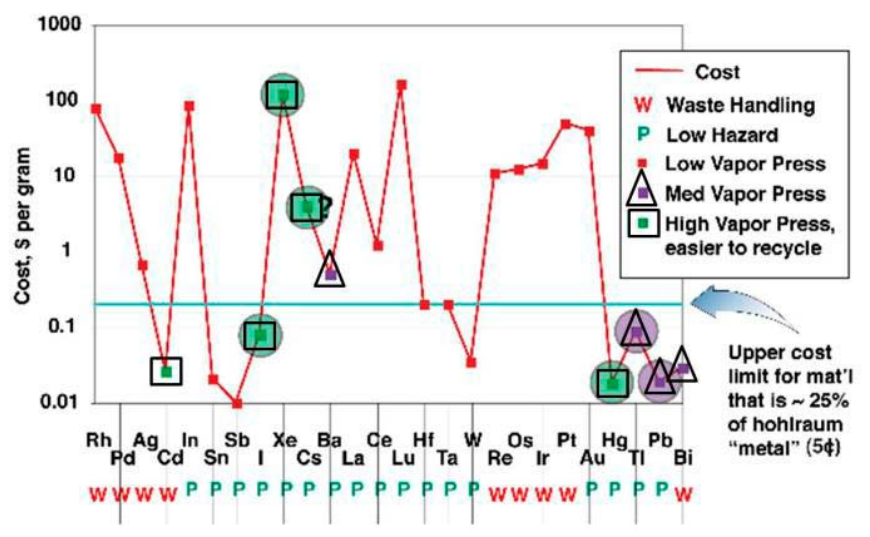

Fig. 6. Cost, vapor-pressure based debris removal and waste disposal selection criteria for the high-Z layer of the hohlraum.

\section{MANUFACTURING CONSIDERATIONS}

Manufacturing cost is a prime consideration for both the choice of target material and the specific target geometry. Ideally, the selected material will constitute a small fraction of the overall target cost so that potentially expensive recycling of the material can be avoided. The bulk of the target costs come from processing steps. The process steps can be separated into mechanical and chemical processes. A strategy for lowering production costs is to use conventional high-throughput manufacturing techniques such as die-casting or stamping for the mechanical processes and increasing the batch size 
of chemical processes such as chemical vapor deposition (CVD) and electroplating processes to increase throughput. A preliminary cost analysis suggests that the per-target cost can be less that 30 cents (Fig. 7) provided that these processes are successfully developed. ${ }^{5}$ A breakout of the costs shown in Fig 8 shows that the material costs for lead hohlraums and a CVD diamond capsule ablator costs are a relatively small part of the target costs $(\sim 17 \%)$ while the equipment costs are a relatively large fraction $(\sim 42 \%)$ of the overall target cost. This is a result of the large number of plasma CVD coating machines required to produce the $\sim 1.3$ million capsules per day even with the large batch size $(\sim 45,000$ per batch) that is postulated following development of a large CVD machine.

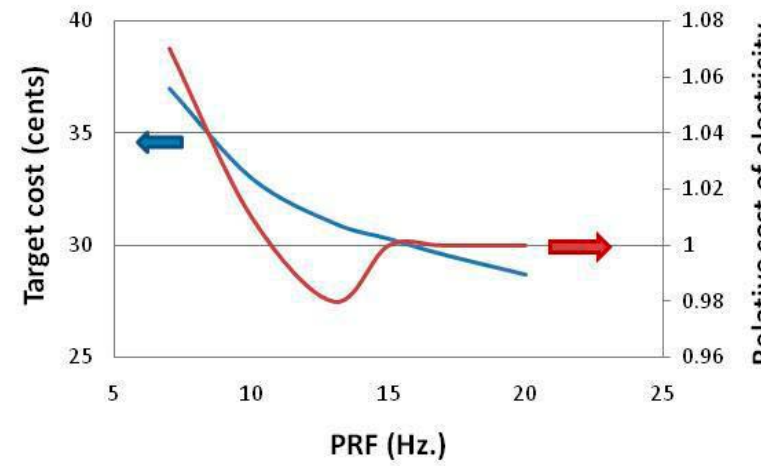

Fig. 7. Per-target cost versus target repetition rate.

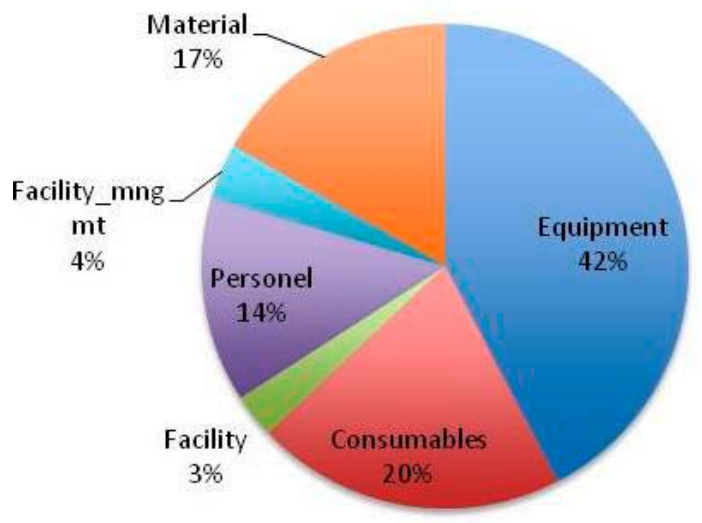

Fig. 8. Breakout of the per-target cost.

\section{INJCTION-TRACKING CONSIDERATIONS}

Another design consideration of the target is to incorporate features necessary for tracking the target trajectory through the chamber such that it will connect with the laser driven beams to within $\sim 100 \mu \mathrm{m}$ of the designed impact point. The distance between the muzzle end of the injector and the chamber center is set by the maximum neutron flux that can be tolerated by the DT layer whose temperature can be unacceptably increased by interaction with the neutrons or by any component parts of the injector system which may experience unacceptable neutron damage. A shuttered neutron shield system located between the injector and the chamber as shown in Fig. 9 can be used to reduce the neutron and gamma radiation to the target. The shutter consists of a spinning wheel of radiation absorbing material such as steel and concrete with slots along the axial length which allow the target to pass through during flight into the chamber but are closed during implosion events to shield the subsequent target. Calculations show that the temperature of the DT layer rises less than $10 \mathrm{mK}$ for a muzzle located at a $10 \mathrm{~m}$ distance from fusion chamber center. A steering section may be added between the injector and the shutter to adjust the target trajectory following injection acceleration if needed. The necessity for the steering section will be determined experimentally.

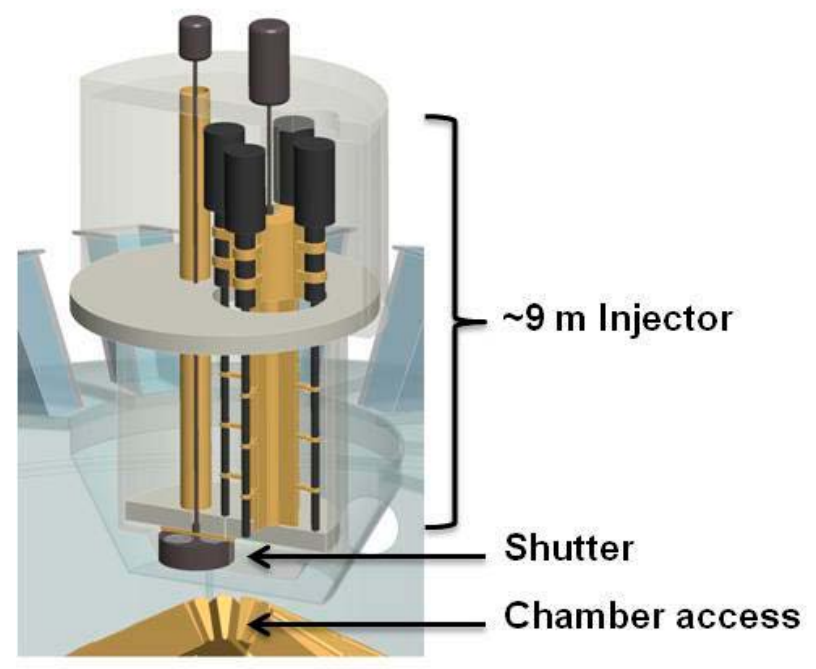

Fig. 9 .Injection system for the LIFE target.

The shorter the distance between the injector muzzle and the chamber center the more accurately the target is likely to be placed in fusion chamber center. Injection accuracy depends on the dimensional quality of the injector and the mitigation of vibrational disturbances. The objective is to place the targets within a $\pm 500 \mu \mathrm{m}$ lateral dimension perpendicular to the target trajectory at chamber center which is equal to the expected range of motion of the laser pointing system for final optics placed at $20 \mathrm{~m}$ from chamber center. The tracking system measures the position and velocity of the target as it traverses the chamber and will consist of a set of crossing 
laser beams which will be triggered by the external shape of the target as shown in Fig. 10. A similar system is described in Ref. 6. It is expected that the target can be tracked to within about $\pm 50 \mu \mathrm{m}$ with reference to the chamber center. When the target is within about $25 \mu$ s of the chamber center ( $\sim 6 \mathrm{~mm}$ for a $250 \mathrm{~m} / \mathrm{s}$ target velocity), the engagement sensors, which use the same optics as the laser, measure the position of the target relative to the pointing direction of the laser to within an expected accuracy of $\pm 10 \mu \mathrm{m}$ and corrects the laser pointing direction to impact the target to well within the $\pm 100 \mu \mathrm{m}$ positional specification. Any changes in velocity or expected position of the target as determined by the tracking system are corrected by the engagement sensors. The engagement system requires that the front and aft faces of the target reflect the external glint laser light in a precisely defined pattern such as a ring pattern such that the engagement sensors can accurately predict the target's position.

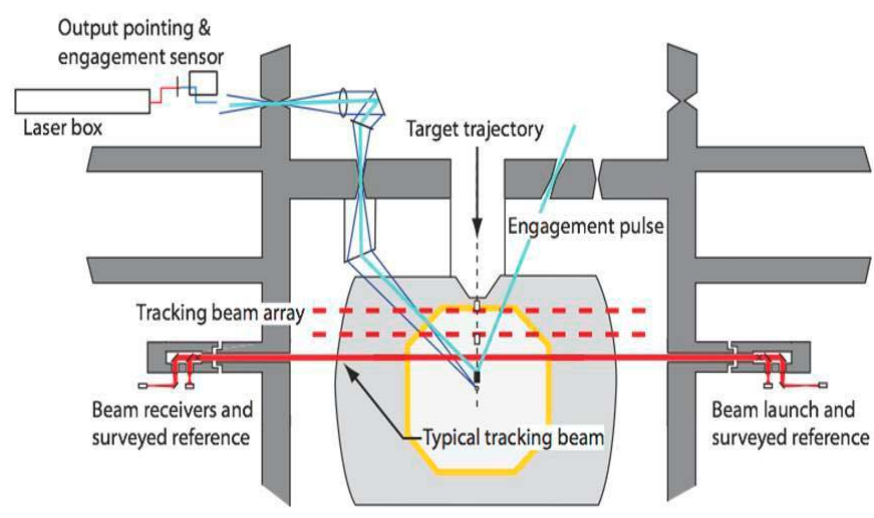

Fig. 10. Tracking and engagement sensor schematic.

\section{CONCLUSION}

A summary of the many of the challenges of the injection of the target into the fusion chamber have been presented. Several design considerations for the LIFE target have been discussed. Considerations include the requirement to accurately inject the target into the fusion chamber center so that the laser can be pointed to intercept the target. Preliminary analyses show that the target can be designed to survive the physical rigors of the injection acceleration into the fusion chamber and the exposure to the hot chamber thermal environment. Considerations for removal of debris from the chamber depend on the choice of material, particularly the hohlraum material. Target costs can be minimized by selecting low-cost materials and by developing large-scale manufacturing processes. Preliminary solutions to these issues have been identified with more extensive analysis in progress.

\section{ACKNOWLEDGMENTS}

This work performed under the auspices of the U.S. Department of Energy by Lawrence Livermore National Laboratory under Contract DE-AC52-07NA27344.

\section{REFERENCES}

1. P. AMENDT, et. al., "LIFE Pure-Fusion Target Designs: Status and Future", $19^{\text {th }}$ Topical Meeting on the Technology of Fusion Energy, Las Vegas, NV, November 7-11, 2010, to be published in the Journal of Fusion Science and Technology.

2. J. F. LATKOWSKI, et. al., "Chamber Design for the Laser Inertial Fusion-based Energy (LIFE) Engine", $19^{\text {th }}$ Topical Meeting on the Technology of Fusion Energy, Las Vegas, NV, November 7-11, 2010, to be published in the Journal of Fusion Science and Technology.

3. P. C. SOUERS, Hydrogen Properties for Fusion Energy, University of California Press, Berkeley, CA (1986).

4. S. P. TIMOSHENKO AND S. WOINOWSKYKRIEGER, Theory of Plates and Shells, McGrawHill, New York, NY (1959).

5. R. R. MILES et. al., "LIFE Target Fabrication Costs", Lawrence Livermore National Laboratory Report, LLNL-TR-416932 (2009).

6. L. CARLSON et. al., "Target Tracking and Engagement for Inertial Fusion Energy - A Tabletop Demonstration", Fusion Science and Technology, 52 (2008) 478-482. 